Experimental Psychology 59(6) (C) 2010 by Hogrefe Publishing.

http://dx.doi.org/10.1027/1618-3169/a000162

"This article may not exactly replicate the final version published in Experimental Psychology. It is not the version of record and is therefore not suitable for citation." 
1 Social support influences preferences for feminine facial cues in

2 potential social partners

3

4 Christopher D Watkins ${ }^{1}$, Lisa M DeBruine ${ }^{1}$, Anthony C Little ${ }^{2}$ \& Benedict C

5 Jones $^{1}$

6

$7 \quad{ }^{1}$ Face Research Laboratory, School of Psychology, University of Aberdeen,

8 Aberdeen, AB24 3FX, Scotland, UK.

$9{ }^{2}$ School of Natural Sciences, University of Stirling, Stirling, FK9 4LA,

10 Scotland, UK.

11

12 Corresponding authors

13 Christopher D Watkins, University of Aberdeen, Scotland, UK.

14 Tel: +44 (0)1224 273933

15 Fax: +44 (0)1224 273426

16 Email: r01cdw9@abdn.ac.uk

17

18 
19

20

21

22

23

24

25

26

28

29

30

31

32

33

34

35

36

37

38

39

40

41

42

43

44

\section{Social support influences preferences for feminine facial cues in} potential social partners

\section{(1)}

\section{Abstract}

Most previous studies of individual differences in women's and men's preferences for sexually dimorphic physical characteristics have focused on the importance of mating-related factors for judgments of opposite-sex individuals. Although studies have suggested that people may show stronger preferences for feminine individuals of both sexes under conditions where social support may be at a premium (e.g., during phases of the menstrual cycle where raised progesterone prepares women's bodies for pregnancy), these studies have not demonstrated that perceptions of available social support directly influence femininity preferences. Here we found that (1) women and men randomly allocated to low social support priming conditions demonstrated stronger preferences for feminine shape cues in own- and opposite-sex faces than did individuals randomly allocated to high social support priming conditions and (2) that people perceived men and women displaying feminine characteristics as more likely to provide them with highquality social support than those displaying relatively masculine characteristics. Together, these findings suggest that social support influences face preferences directly, potentially implicating facultative responses whereby people increase their preferences for pro-social individuals under conditions of low social support. 


\section{Introduction}

Recent studies suggest that masculine and feminine physical characteristics are associated with a wide range of traits in men and women (see Little, Jones \& DeBruine, 2011 and Puts, 2010 for recent reviews). For example, several studies have demonstrated that individuals displaying relatively feminine facial characteristics tend to be ascribed pro-social personality characteristics, such as emotional warmth and stronger parental tendencies, while individuals displaying relatively masculine facial characteristics tend to be ascribed anti-social personality characteristics, such as dominance and untrustworthiness (e.g., Perrett et al., 1998). Moreover, other research suggests that many of these personality attributions may be somewhat accurate (e.g., Law Smith et al., in press; Roney, Hanson, Durante \& Maestripieri, 2006). While these findings suggest that masculine and feminine physical characteristics may signal aspects of men's and women's personalities, they may also signal aspects of physical condition. For example, some research suggests that exaggerated sex-typical characteristics in men and women (i.e., masculine characteristics in men and feminine characteristics in women) are positively correlated with measures of men's and women's long-term health (e.g., Thornhill \& Gangestad, 2006) and other putative health cues (e.g., Little et al., 2008), while other work suggests that masculine characteristics are positively correlated with measures of physical strength (Fink, Neave \& Seydel, 2007; Puts, Apicella \& Cardenas, 2011; see also Sell et al., 2009). Collectively, these findings highlight the potentially important role that sexually dimorphic physical characteristics could play in signaling information that may be highly relevant to social interaction in 
humans. However, it is important to note that, although studies have consistently demonstrated strong preferences for feminine characteristics in women's faces, preferences for masculine characteristics in men's faces are considerably more variable, with studies variously reporting preferences for masculine characteristics, preferences for feminine characteristics, and no effect of masculinity-femininity on men's facial attractiveness (for a metaanalytic review see Rhodes, 2006). These latter findings of variable attractiveness judgments of men's appear to reflect systematic individual differences in the type of men's faces that are considered optimally attractive (e.g., DeBruine et al., 2006).

To date, most research on individual differences in men's and women's preferences for sexually dimorphic physical characteristics in others has focused on mate preferences by examining individual differences in the importance people place on the traits signaled by sexually dimorphic characteristics in opposite-sex individuals (see Little et al., 2011 and Scott, Clark, Boothroyd \& Penton-Voak, in press for recent reviews). For example, women appear to demonstrate stronger preferences for masculine men during the fertile phase of menstrual cycle than at other times, particularly when asked to assess men's attractiveness for hypothetical short-term, rather than long-term, relationships (e.g., Gangestad, Simpson \& Cousins, 2004; Johnston, Hagel, Franklin, Fink \& Grammer, 2001; Little \& Jones, in press; Penton-Voak et al., 1999). A possible explanation for these findings is that, around ovulation, women place greater emphasis on cues to the physical condition of potential short-term mates that may be heritable (Gangestad et 

al., 2004; Johnston et al., 2001; Little \& Jones, in press; Penton-Voak et al., 1999), although this interpretation remains somewhat controversial (see Jones et al., 2008 and Scott et al., in press for discussion). Other studies have reported that men and women reporting higher levels of sexual desire demonstrate stronger preferences for exaggerated sex-typical characteristics in opposite-sex faces (Jones, Little, Watkins, Welling \& DeBruine, 2011; Welling, Jones \& DeBruine, 2008a) and that these preferences are also stronger when participants' salivary testosterone levels are high than when their salivary testosterone levels are relatively low (Welling et al., 2007, 2008b; see also Roney, Simmons \& Gray, $2011^{1}$ ). Together these findings also suggest that individual differences in preferences for sexually dimorphic characteristics are shaped, at least partly, by mating-related factors, such as sex drive and associated hormone levels.

While most previous studies of individual differences in preferences for sexually dimorphic physical characteristics have focused on the importance of mating-related factors and judgments of opposite-sex individuals, there may also be substantial benefits to forming social alliances with both own-sex and opposite-sex individuals displaying cues to pro-social personality traits (for recent reviews see Barclay, 2011 and Queller, 2011). For example, individuals who form alliances with pro-social social partners may obtain reputational benefits associated with forming strong cooperative partnerships (e.g., Fehr, 2004) and/or benefit from the pooling of resources (e.g., Fehr \&

\footnotetext{
${ }^{1}$ We note here that, although Roney et al. (2011) suggested that their effect of salivary testosterone level on women's masculinity preferences was not significant, the two-tailed p-value was <.10. Given the previous study by Welling et al. (2007), which had demonstrated a significant effect of testosterone level, a one-tailed test would be justified in Roney et al's study and would be significant. This is particularly noteworthy since Roney et al. (2011) tested approximately half as many women as Welling et al. (2007).
} 
118 Gachter, 2002). Additionally, forming alliances with pro-social individuals may

119 confer substantial benefits because of the large positive effect that social

120 support has on long-term health outcomes. For example, a recent meta-

121 analysis of longitudinal studies of the effects of social support on health

122 outcomes found that individuals with good social support were $50 \%$ more

123 likely to be alive at follow-up tests than were individuals with poor social

124 support (Holt-Lunstad, Smith \& Layton, 2010). Moreover, this effect of social

125 support on survival rates was consistent across participant age, sex, initial

126 health status, and length of follow-up period (Holt-Lunstad et al., 2010).

127 Importantly, individuals with little social support may gain the most from

128 prioritizing pro-social traits when assessing the suitability (i.e., attractiveness)

129 of potential social partners, raising the possibility that social support could be

130 an important factor in women's and men's preferences for feminine versus

131 masculine individuals. Consistent with this proposal, some previous research

132 has suggested that individuals may well demonstrate stronger preferences for

133 feminine individuals under conditions where social support is likely to be at a

134 premium, such as when they are primed with cues to harsh environments

135 (Little, Cohen, Jones \& Belsky, 2007), during menstrual cycle phases where

136 raised progesterone levels prepare women's bodies for pregnancy (Jones et

137 al., 2005), or when a particularly large family is planned (Moore, Law Smith,

138 Cassidy \& Perrett, 2009; Moore, Law Smith, Taylor \& Perrett, 2011).

139 Importantly, however, these studies presented no direct evidence that social

140 support influences femininity preferences (Jones et al., 2005; Little et al.,

141 2007; Moore et al., 2009, 2011) and have generally assessed participants' 
142 preferences for femininity in potential mates only (Little et al., 2007; Moore et 143 al., 2009, 2011).

145 The current experiment investigated the role of social support in men's and 146 women's preferences for feminized versus masculinized versions of own-sex

147 and opposite-sex faces. Specifically, we investigated if men's and women's

148 preferences for feminized versus masculinized faces can be altered by

149 randomly allocating participants to priming conditions in which they were

150 instructed to imagine a time when they either received a great deal of social

151 support from their friends or family (high social support conditions) or received

152 very little social support from their friends or family (low social support

153 conditions). If social support plays a direct role in preferences for feminine

154 individuals, one would expect that participants in the low social support

155 conditions would show stronger preferences for feminine individuals than

156 participants in the high social support conditions. An important advantage of

157 using this type of priming paradigm is that it allows for firm conclusions to be

158 drawn about the nature of the causal link between social support and

159 attractiveness judgments.

161 Methods

162 Participants

163 One hundred and six participants $(76$ women and 30 men; mean age $=22.3$

164 years, $S D=4.61$ years) took part in our main experiment. These participants

165 were recruited for an online study of face perception by following links from

166 social bookmarking Web sites (e.g., stumbleupon). Prior research has 
167 established that lab-based and online studies of face perception produce very

168 similar patterns of results (e.g., Conway, Jones, DeBruine \& Little, 2008;

169 Wilson \& Daly, 2004; Senior et al., 1999a, 1999b).

171 Face stimuli

172 Following previous studies of perceptions of masculine versus feminine faces

173 (e.g., DeBruine et al., 2006; DeBruine, Jones, Smith \& Little 2010), we used

174 prototype-based image transformations to objectively manipulate sexual

175 dimorphism of 2D shape in digital face images. Although different methods for

176 manipulating masculinity of face images have been used in some other

177 studies (e.g., Johnston et al., 2001), these methods have been shown to

178 produce effects on person perception that are equivalent to those produced

179 using the methods in our current study (see, e.g., DeBruine et al., 2006, 180 2010).

182 First, male and female prototype (i.e., average) faces were manufactured 183 using established computer graphic methods that have been widely used in 184 studies of face perception (e.g., DeBruine et al., 2006, 2010; Penton-Voak et 185 al., 1999; Welling et al., 2007). Prototypes are composite images that are 186 constructed by averaging the shape, color, and texture of a group of faces, 187 such as male or female faces. These prototypes can then be used to 188 transform images by calculating the vector differences in position between 189 corresponding points on two prototype images and changing the position of 190 the corresponding points on a third image by a given percentage of these 191 vectors (see Rowland \& Perrett, 1995 and Tiddeman, Burt \& Perrett, 2001 for 
192 technical details). Here, a male prototype was manufactured by averaging the

193 shape, color, and texture information from face images of 20 young White

194 men (mean age $=19.5$ years, $S D=2.3$ years). A female prototype was

195 manufactured by averaging the shape, color, and texture information from

196 face images of 20 young White women (mean age $=18.4$ years, $S D=0.7$

197 years).

198

199 Next, $50 \%$ of the linear differences in 2D shape between symmetrized

200 versions of the male and female prototypes were added to or subtracted from

201 face images of 10 young White men (mean age $=21.4$ years, $S D=5.4$ years)

202 and 10 young White women (mean age $=18.1$ years, $S D=0.7$ years). This

203 process created masculinized and feminized versions of each individual face

204 image. The masculinized and feminized versions differed in sexual

205 dimorphism of 2D shape and were matched in other regards (e.g., identity,

206 skin color and texture, Rowland \& Perrett, 1995). Examples of masculinized

207 and feminized face images are shown in Figure 1. Thus, 20 pairs of images

208 were produced in total, consisting of 10 pairs of female face images and 10

209 pairs of male face images (each pair consisting of a masculinized and a

210 feminized version of the same individual).

211

212 FIGURE 1 AROUND HERE

213

214 Manipulation check 1: Does manipulating face shape alter masculinity

215 and femininity perceptions? 
216 To establish whether our masculinized and feminized face stimuli differed in

217 perceived masculinity-femininity in the intended manner, we presented the 20

218 pairs of images (each pair consisting of a masculinized and a feminized

219 version of the same individual) in a fully randomized order to participants (38

220 women, 20 men; mean age $=21.90$ years, $S D=4.04$ years). The side of the

221 screen on which any given image was presented was also randomized. Half

222 of the participants were instructed to indicate which image in each pair looked

223 more masculine and the other half were instructed to indicate which image in

224 each pair looked more feminine. None of the participants who took part in this 225 manipulation check participated in the main experiments.

227 One-sample t-tests showed that the proportion of trials on which participants 228 who were asked to judge the femininity of the face images correctly identified 229 the feminized versions was significantly greater than the chance value of 0.5 230 for judgments of both women's faces $(t(28)=18.0, p<.001, M=.92, S E M=$ $231.02, d=3.33)$ and men's faces $(t(28)=103.0, p<.001, M=.99, S E M=.01, d$ $232=19.1)$. Similarly, the proportion of trials on which participants who were 233 asked to judge the masculinity of the face images correctly identified the 234 masculinized versions was significantly greater than chance for judgments of 235 both women's faces $(t(28)=8.46, p<.001, M=.86, S E M=.04, d=1.57)$ and 236 men's faces $(t(28)=12.1, p<.001, M=.94, S E M=.04, d=2.25)$. These

237 findings demonstrate that our methods for manipulating sexually dimorphic 238 aspects of 2D face shape produce stimuli that differ in perceived masculinity239 femininity in the intended manner (see also, e.g., DeBruine et al., 2006, 2010; 240 Jones et al., 2010). 
242 Manipulation check 2: Does manipulating face shape alter social

243 support perceptions?

244 We undertook an additional manipulation check to establish whether

245 individuals displaying feminized facial characteristics were perceived as more

246 supportive. Each participant (92 women, 49 men; mean age $=21.85$ years,

$247 S D=4.82$ years) was shown the 20 pairs of faces (each pair consisting of a

248 masculinized and feminized version of the same face) and were instructed to

249 click on the face of the person they thought would be more likely to provide

250 them with social support or that they thought would provide them with better

251 quality social support. The order in which the pairs of face images were

252 shown was fully randomized, as was the side of the screen on which the

253 masculinized and feminized versions were presented.

254

255 One-sample t-tests showed that participants perceived feminine individuals as

256 more likely to provide them with social support than masculine individuals

257 when judging both women's faces $(M=.67$, SEM $=.03, t(65)=5.96, p<.001$, $258 d=0.73)$ and men's faces $(M=.68$, SEM $=.02, t(65)=7.52, p<.001, d=$

259 0.93). Similarly, participants perceived feminine individuals as likely to provide

260 them with better quality social support than masculine individuals when

261 judging both women's faces $(M=.68$, SEM $=.02, t(74)=8.60, p<.001, d=$

262 1.03) and men's faces $(M=.70$, SEM $=.02, t(74)=9.16, p<.001, d=1.06)$.

263 These findings confirm that feminine facial characteristics influence support-

264 related perceptions. 
266

267

268

269

270 In the initial priming phase of the experiment, each participant was randomly

271 allocated to one of four conditions: a condition where they were instructed to

272 imagine a scenario where they received a lot of support from their family

$273(\mathrm{~N}=30)$, a condition where they were instructed to imagine a scenario where

274 they received little support from their family $(\mathrm{N}=26)$, a condition where they

275 were instructed to imagine a scenario where they received a lot of support

276 from their friends $(\mathrm{N}=18)$, or a condition where they were instructed to imagine

277 a scenario where they received little support from their friends $(N=32)$.

278 Participants were given the following instructions: "Please take a moment to

279 imagine a time when you felt very [close to/isolated from] your [family/friends]

280 and felt that you received [a lot of/little] emotional support from them." They

281 then rated how vividly they had imagined the scenario on a 1 (not very vivid)

282 to 7 (very vivid) scale (mean $=4.35, S D=2.16)$. Recent work on the effects of

283 imagery on perception has shown that participants can accurately rate the

284 vividness of their mental imagery (Pearson, Rademaker \& Tong, 2011). Our

285 priming paradigm was adapted from that used by Smith, Ruiz and Uchino

286 (2004) to prime social support schema. We included source of support (family,

287 friends) as a factor in our experimental design because some researchers

288 have proposed that the source of support may be important for the strength of

289 the relationships between social support and health factors, though empirical

290 findings on this point have been mixed (see Thoits, 1995). Additionally, we 
291 emphasized emotional support in our priming manipulation because many

292 studies have identified emotional support as being a particularly important

293 facet of social support (reviewed in Uchino, Cacioppo \& Kiecolt-Glaser, 1996).

294

295 Immediately after the initial priming phase of the experiment, participants

296 completed a femininity preference test. The method we used to assess

297 individual differences in preferences for feminized versus masculinized

298 versions of faces has been used in many previous studies of systematic

299 variation in face preferences (e.g., Buckingham et al., 2006; Welling et al.,

300 2008b). Participants were shown the 20 pairs of faces and were instructed to

301 indicate which face in each pair they thought was the more attractive.

302 Participants were also instructed to indicate how much more attractive they

303 thought the chosen face was (relative to the other face in the pair) by

304 choosing from the options "much more attractive", "more attractive",

305 "somewhat more attractive", and "slightly more attractive". The order in which

306 the pairs of face images were shown was fully randomized, as was the side of

307 the screen on which the masculinized and feminized versions were presented.

308

309 Initial processing of data

310 Following many previous studies of individual differences in face preferences

311 (e.g., Buckingham et al., 2006; Welling et al., 2008b), responses on the face

312 preference test were coded using the following scale: 
3140 to 3: masculinized face rated 'much more attractive' $(=0)$, 'more attractive'

$315(=1)$ 'somewhat more attractive' $(=2)$ or 'slightly more attractive' $(=3)$ than

316 feminized face.

3184 to 7 : feminized face rated 'slightly more attractive' $(=4)$, 'somewhat more

319 attractive' $(=5)$, 'more attractive' $(=6)$ or 'much more attractive' $(=7)$ than

320 masculinized face.

322 For each participant, we calculated their average score for judgments of the

32310 male faces. Separately, we also calculated their average score for

324 judgments of the 10 female faces. These femininity preference scores were

325 used in subsequent analyses. Higher scores indicate stronger attraction to

326 feminized faces. These data are summarized in Table 1.

INSERT TABLE 1 AROUND HERE

\section{Results}

331 One-sample t-tests comparing scores on the face preference test with what

332 would be expected by chance alone (i.e., 3.5) showed that participants

333 generally rated feminized versions of women's faces as more attractive than

334 masculinized versions $(t(105)=12.0, p<.001, M=4.23, S E M=.06, d=$

335 1.16). By contrast, scores for men's faces were not significantly different from chance $(t(105)=0.12, p=.91, M=3.51, S E M=.07, d=0.01)$. Similar results

337 were obtained when we analyzed men's and women's responses separately; 338 both sets of analyses revealed significant effects of femininity on perceptions 
339 of women's, but not men's, facial attractiveness. These findings are consistent

340 with previous work that has consistently demonstrated strong preferences for

341 feminine characteristics in women's faces, but has shown preferences for

342 masculinity-femininity in men's faces to be considerably more variable (for a

343 meta-analytic review see Rhodes, 2006). This variability appears to reflect

344 systematic variation in the extent to which people prefer masculine or

345 feminine men (see Little et al., 2011 for a recent review of possible sources of 346 these individual differences).

348 Next, we carried out a mixed-design ANOVA with sex of face (male, female)

349 as a within-subjects factor and source of support (family, friends), quantity of 350 support (high, low), and participant sex (male, female) as between-subjects 351 factors. This analysis revealed a significant effect of sex of face $(F(1,98)=$ $35252.5, p<.001$, partial eta ${ }^{2}=.35$ ), whereby preferences for femininity in 353 women's faces $(M=4.23, S E M=.06)$ were significantly stronger than

354 preferences for femininity in men's faces $(M=3.51, S E M=.07)$. We also 355 observed a significant main effect of quantity of support $(F(1,98)=5.76, p=$ 356.018 , partial eta $\left.{ }^{2}=.06\right)$, whereby participants allocated to the low social 357 support priming conditions subsequently demonstrated stronger preferences 358 for feminized faces $(M=3.95, S E M=0.07)$ than did participants allocated to 359 the high social support priming conditions $(M=3.77, S E M=0.07)$. When 360 analyzing judgments of men's and women's faces separately, one-sample t361 tests against the chance value of 3.5 showed that participants preferred 362 feminized to masculinized versions of women's faces in both the low $(t(57)=$ 363 9.58, $p<.001, d=1.25)$ and high $(t(47)=7.27, p<.001, d=1.04)$ social 
364 support priming conditions. Corresponding t-tests for judgments of men's

365 faces showed that participants tended to prefer feminized to masculinized

366 versions in the low social support priming conditions $(t(57)=1.43, p=.15, d=$

3670.18 ) and tended to prefer masculinized to feminized versions in the high

368 social support priming conditions $(t(47)=-1.57, p=.12, d=0.22)$, though

369 neither preference was significantly different from chance. A main effect of

370 participant sex, whereby women's femininity preferences $(M=3.91, S E M=$

$371.05)$ tended to be stronger than men's $(M=3.78$, SEM $=.12)$, approached

372 significance $\left(F(1,98)=3.13, p=.080\right.$, partial eta $\left.{ }^{2}=.03\right)$. A three-way

373 interaction among sex of face, source of support, and participant sex also

374 approached significance $\left(F(1,98)=3.08, p=.082\right.$, partial eta $\left.{ }^{2}=.03\right)$. Because

375 we had not predicted this interaction, and because it did not involve our main

376 factor of interest (quantity of support), we did not explore it further. No other

377 main effects or interactions among any of our variables were significant or

378 approached significance (all $F(1,98)<1.77$, all $p>.18$, all partial eta $^{2}<.02$ ).

380 The main effect of quantity of support remained significant when vividness

381 ratings were included as a covariate $\left(F(1,97)=6.34, p=.013\right.$, partial eta ${ }^{2}=$

382 .06). This latter finding indicates that the effect of quantity of support on face

383 preferences was not an artifact of differences in the vividness with which

384 participants imagined the different priming scenarios.

385

386 Discussion

387 We found that individuals randomly allocated to the low social support priming

388 conditions demonstrated stronger preferences for feminine faces than did 
389 individuals randomly allocated to the high social support priming conditions. In 390 our manipulation checks (see Methods), we also showed that participants 391 perceived men and women displaying feminized facial characteristics to be 392 more likely to provide them with high-quality social support than individuals 393 displaying masculinized facial characteristics. Collectively, these findings 394 suggest that preferences for pro-social individuals are increased under 395 conditions of low social support and that perceptions of available social 396 support play a potentially important role in individual differences in face 397 preferences. Importantly, the priming effects observed in our main experiment 398 were equivalent for judgments of own-sex and opposite-sex individuals, 399 suggesting that they reflect general preferences for potential social partners, 400 rather than more specific preferences that are primarily relevant to 401 assessments of potential mates. Note, however, that while participants 402 demonstrated significant preferences for feminized versions of women's faces 403 in both the high and low support conditions, preferences for feminine versus 404 masculine men did not differ significantly from chance in either of these 405 conditions. This pattern of results is consistent with prior work demonstrating 406 that sexually dimorphic shape cues have greater effects on women's than 407 men's facial attractiveness (see, e.g., Rhodes, 2006).

409 Stronger attraction to feminine individuals in the low social support conditions

410 suggest facultative responses whereby preferences for supportive social 411 partners are increased under conditions of low social support. Such facultative 412 responses may be adaptive because of the benefits that appear to be 413 associated with forming alliances with supportive individuals, such as the 
414 reputational benefits associated with forming strong cooperative partnerships

415 (e.g., Fehr, 2004), the pooling of resources (e.g., Fehr \& Gachter, 2002), and

416 substantially increased long-term health (for a meta-analytic review see Holt-

417 Lunstad et al., 2010). While previous research on individual differences in

418 preferences for sexually dimorphic cues in faces has tended to focus on mate

419 preferences (see Little et al., 2011 and Scott et al., in press for reviews), here

420 we emphasize the effects of social support on assessments of the

421 attractiveness of both own- and opposite-sex individuals. While some

422 previous studies have presented indirect evidence that individuals

423 demonstrate stronger preferences for feminine individuals under conditions

424 where social support is likely to be at a premium, such as when raised

425 progesterone during the luteal (non-fertile) phase of the menstrual cycle

426 prepares women's bodies for pregnancy (Jones et al., 2005), under harsh

427 environmental conditions (Little et al., 2007), or when a particularly large

428 family is desired (Moore et al., 2009, 2011), ours is the first experiment that

429 we are aware of to present evidence that perceptions of available social

430 support directly influence face preferences. Moreover, our findings

431 complement those from other recent work suggesting compensatory

432 responses under conditions of low social support, whereby people are more

433 likely to attend to signals of social acceptance when they feel socially

434 excluded (DeWall, Maner \& Rouby, 2009) and are more likely to trust others

435 when their romantic relationships are under stress (Koranyi \& Rothermund,

436 2012). Thus, our findings add to a growing literature demonstrating

437 compensatory behavioral responses to support-related social factors.

438 Although the priming effect in the current experiment was relatively small, the 
439 small effect size elicited by this 'minimal manipulation' suggests that the

440 corresponding effect in the real world could well be substantial (see Prentice

441 \& Miller, 1992 for discussion).

443 Although the current experiments suggest that participants in post-

444 industrialized societies perceive feminine individuals to be particularly

445 supportive and modulate their femininity preferences in response to social

446 support factors, the extent to which these findings generalize to other

447 populations is unknown. While some work has shown that attributions of

448 behavioral characteristics to individuals based on facial cues alone can be

449 somewhat stable across cultures (e.g., Perrett et al., 1998), the possibility that

450 there may be differences in these attributions between more diverse cultures

451 has received relatively little attention. We suggest that cross-cultural work on

452 both personality attributions and the role of social support in face preferences

453 may prove to be a fruitful line of inquiry for future research. Indeed, while a

454 lack of social support appears to increase preferences for cues of pro-sociality

455 in relatively predictable, and therefore relatively safe, environments, lack of

456 social support in less predictable environments may increase preferences for

457 cues associated with different factors, such as markers of resource holding

458 potential. We suggest that investigating how these environmental factors

459 interact with the effects of social support observed in the current experiments

460 is also likely to be a fruitful line of research.

461

462 In conclusion, our results show that priming participants by having them

463 imagine scenarios in which they received either a great deal of or little social 
464 support modulates their preferences for facial cues associated with perceived

465 pro-sociality (i.e., feminine shape cues) in men's and women's faces. We

466 suggest that these findings are likely to reflect facultative responses that may

467 have evolved to increase the potential benefits available from forming

468 alliances with pro-social individuals when social support was otherwise

469 lacking. More fundamentally, our data present direct evidence that social

470 support helps to shape the extent to which we value potential cues to pro-

471 sociality in social partners.

472

473 


\section{References}

Barclay, P. (2011). Competitive helping increases with the size of biological markets and invades defection. Journal of Theoretical Biology, 281, 4755.

Buckingham, G., DeBruine, L. M., Little, A. C., Welling, L. L. M., Conway, C. A., Tiddeman, B. P. \& Jones, B. C. (2006). Visual adaptation to masculine and feminine faces influences generalized preferences and perceptions of trustworthiness. Evolution and Human Behaviour, 27, 381-389.

Conway, C. A., Jones, B. C., DeBruine, L. M. \& Little, A. C. (2008). Evidence for adaptive design in human gaze preference. Proceedings of the Royal Society of London B, 275, 63-69.

DeBruine, L. M., Jones, B. C., Smith, F. G. \& Little, A. C. (2010). Are attractive men's faces masculine or feminine? The importance of controlling confounds in face stimuli. Journal of Experimental Psychology: Human Perception and Performance. 36, 751-758.

DeBruine, L. M., Jones, B. C., Little, A. C., Boothroyd, L. G., Perrett, D. I., Penton-Voak, I. S., Cooper, P. A., Penke, L., Feinberg, D. R. \& Tiddeman, B. P. (2006). Correlated preferences for facial masculinity and ideal or actual partner's masculinity. Proceedings of the Royal Society of London B, 273, 1355-1360.

DeWall, C. N., Maner, J. K. \& Rouby, D. A. (2009). Social exclusion and earlystage interpersonal perception: Selective attention to signs of acceptance. Journal of Personality and Social Psychology, 96, 729741. 
499 Fehr, E. (2004). Don’t lose your reputation. Nature, 432, 449-450.

500 Fehr, E. \& Gachter, S. (2002). Altruistic punishment in humans. Nature, 415, 137-140.

502 Fink, B., Neave, N. \& Seydel, H. (2007). Male facial appearance signals physical strength to women. American Journal of Human Biology, 19, 82-87.

505 Gangestad, S. W., Simpson, J. A. \& Cousins, A. J. (2004). Women's preferences for male behavioural displays change across the menstrual cycle. Psychological Science, 15, 203-207.

508 Holt-Lunstad, J., Smith, T. B. \& Layton, J. B. (2010). Social relationships and mortality risk: A meta-analytic review. PLoS Medicine, 7, e1000316.

510 Johnston, V. S., Hagel, R., Franklin, M., Fink, B. \& Grammer, K. (2001). Male facial attractiveness: evidence for hormone mediated design. Evolution and Human Behaviour, 23, 251-267.

513 Jones, B.C., DeBruine, L. M., Main, J.C., Little, A.C., Welling, L.L.M., Feinberg, D.R. \& Tiddeman, B.P. (2010). Facial cues of dominance modulate the short-term gaze-cuing effect in human observers. Proceedings of the Royal Society of London B, 277, 617-624.

517 Jones, B. C., Little, A. C., Watkins, C. D., Welling, L. L. M. \& DeBruine, L. M. (2011). Reported sexual desire predicts men's preferences for sexually dimorphic cues in women's faces. Archives of Sexual Behavior, 40,

521 Jones, B. C., DeBruine, L. M., Perrett, D. I., Little, A. C., Feinberg, D. R. \& Law Smith, M. J. (2008). Effects of menstrual cycle phase on face preferences. Archives of Sexual Behaviour, 37, 78-84. 
524 Jones, B. C., Little, A. C., Boothroyd, L. G., DeBruine, L. M., Feinberg, D. R.,

525 Law Smith, M. J., Cornwell, R. E., Moore, F. R. \& Perrett, D. I. (2005).

526 Commitment to relationships and preferences for femininity and

527 apparent health in faces are strongest on days of the menstrual cycle

528 when progesterone level is high. Hormones and Behavior, 48, 283-290.

529 Koranyi, N. \& Rothermund, K. (2012). Automatic coping mechanisms in

530 committed relationships: Increased interpersonal trust as a response to

531 stress. Journal of Experimental Social Psychology, 48, 180-185.

532 Law-Smith, M. J., Deady, D. K., Moore, F. R., Jones, B. C., Cornwell, R. E.,

Stirrat, M. R., Lawson, J., Feinberg, D. R. \& Perrett, D. I. (in press).

Maternal tendencies in women are associated with estrogen levels and facial femininity. Hormones and Behavior.

Little, A. C. \& Jones, B. C. (in press). Variation in facial masculinity and symmetry preferences across the menstrual cycle is moderated by relationship context. Psychoneuroendocrinology.

539 Little, A. C., Jones, B. C. \& DeBruine, L. M. (2011). Facial attractiveness: Evolutionary based research. Philosophical Transactions of the Royal

542 Little, A. C., Jones, B. C., Waitt, C., Tiddeman, B. P., Feinberg, D. R., Perrett, 
environmental harshness. Behavioral Ecology and Sociobiology, 61, 967-973.

Moore, F. R., Law-Smith, M. J., Taylor, V. \& Perrett, D. I. (2011). Sexual dimorphism in the female face is a cue to health and social status but not age. Personality and Individual Differences, 50, 1068-1073.

Moore, F. R., Law-Smith, M. J., Cassidy, C. \& Perrett, D. I. (2009). Female reproductive strategy predicts preferences for sexual dimorphism in male faces. Journal of Evolutionary Psychology, 7, 211-224.

Pearson, J., Rademaker, R. \& Tong, F. (2011). Evaluating the mind's eye: The metacognition of visual imagery. Psychological Science, in press.

Penton-Voak, I. S., Perrett, D. I., Castles, D., Burt, M., Koyabashi, T. \& Murray, L. K. (1999). Female preference for male faces changes cyclically. Nature, 399, 741-742.

Perrett, D. I., Lee, K. J., Penton-Voak, I. S., Rowland, D. R., Yoshikawa, S., Burt, D. M., Henzi, S. P., Castles, D. I. \& Akamatsu, S. (1998). Effects of sexual dimorphism on facial attractiveness. Nature, 394, 884-887.

Prentice, D. A. \& Miller, D. T. (1992). When small effects are impressive. Psychological Bulletin, 112, 160-164.

Puts, D. A., Apicella, C. L. \& Cardenas, R. A. (2011). Masculine voices signal men's threat potential in foraging and industrial societies. Proceedings of the Royal Society of London B, DOI: 10.1098/rspb.2011.0829.

Puts, D. A. (2010). Beauty and the beast: Mechanisms of sexual selection in humans. Evolution and Human Behavior, 31, 157-175. 
571 Queller, D. C. (2011). Expanded social fitness and Hamilton's rule for kin, kith, and kind. Proceedings of the National Academy of Sciences, 108, 10792-10799.

574 Rhodes, G. (2006). The evolutionary psychology of facial beauty. Annual Review of Psychology, 57, 199-226.

576 Roney, J. R., Simmons, Z. L. \& Gray, P. B. (2011). Changes in estradiol predict within-women shifts in attraction to facial cues of men's testosterone. Psychoneuroendocrinology, 36, 742-749.

Roney, J. R., Hanson, K. N., Durante, K. M. \& Maestripieri, D. (2006). Reading men's faces: women's mate attractiveness judgments track men's testosterone and interest in infants. Proceedings of the Royal Society of London B, 273, 2169-2175.

Rowland, D. A. \& Perrett, D. I. (1995). Manipulating facial appearance through shape and colour. IEEE Computer Graphics and Applications, 15, 7076.

Scott, I. M. L., Clark, A. P., Boothroyd, L. G. \& Penton-Voak, I. S. (in press). Do men's faces really signal heritable immunocompetence? Behavioral

589 Sell, A., Cosmides, L., Tooby, J., Sznycer, D., von Reuden, C., Gurven, M. (2009). Human adaptations for the visual assessment of strength and fighting ability from the body and face. Proceedings of the Royal

593 Senior, C., Barnes, J., Jenkins, R., Landau, S., Philips, M. L. \& David, A. S. (1999a). Attribution of social dominance and maleness to schematic faces. Social Behavior and Personality, 27, 331-338. 
596 Senior, C., Philips, M. L., Barnes, J. \& David, A. S. (1999b). An investigation into the perception of dominance from schematic faces: A study using the World-Wide Web. Behavior Research Methods, Instruments and Computers, 31,341-346.

600 Smith, T. W., Ruiz, J. M. \& Uchino, B. N. (2004). Mental activation of supportive ties, hostility, and cardiovascular reactivity to laboratory stress in young men and women. Health Psychology, 23, 476-485.

Thoits, P. A. (1995). Stress, coping and social support processes: Where are we? What next? Journal of Health and Social Behavior, 36, 53-79.

Thornhill, R. \& Gangestad, S. W. (2006). Facial sexual dimorphism, developmental stability, and susceptibility to disease in men and women. Evolution and Human Behaviour, 27, 131-14.

Tiddeman, B. P., Burt, D. M. \& Perrett, D. I. (2001). Prototyping and transforming facial texture for perception research. IEEE Computer Graphics and Applications, 21, 42-50.

Uchino, B. N., Cacioppo, J. T. \& Kiecolt-Glaser, J. K. (1996). The relationship between social support and physiological processes: a review with emphasis on underlying mechanisms and implications for health. Psychological Bulletin, 119, 488-531.

615 Welling, L. L. M., Jones, B. C. \& DeBruine, L. M. (2008a). Sex drive is positively associated with women's preferences for sexual dimorphism in men's and women's faces. Personality and Individual Differences,

619 Welling, L. L. M., Jones, B. C., DeBruine, L. M., Smith, F. G., Feinberg, D. R., 620 Little, A. C. \& Al-Dujaili, E. A. S. (2008b). Men report stronger attraction 
621

622

623 Welling, L. L. M., Jones, B. C., DeBruine, L. M., Conway, C. A., Law Smith, M.

624

625

626

627 Wilson, M. \& Daly, M. (2004). Do pretty women inspire men to discount the 628

629

630

to femininity in women's faces when their testosterone levels are high. Hormones and Behavior, 54, 703-708.

J., Little, A. C., Feinberg, D. R., Sharp, M. \& Al-Dujaili, E. A. S. (2007). Raised salivary testosterone in women is associated with increased attraction to masculine faces. Hormones and Behaviour, 52, 156-161. future? Proceedings of the Royal Society of London B, 271, S177S179. 
631 Table 1. Mean femininity preference (standard deviation given in brackets) for 632 each condition in our main experiment ( $3.5=$ chance level, i.e., no overall

633 femininity preference). See main text for a full explanation of how the 634 preference score was calculated.

635

\begin{tabular}{ccccc}
\hline & \multicolumn{2}{c}{ high support } & \multicolumn{2}{c}{ low support } \\
\hline & family & friends & family & friends \\
\hline \multicolumn{4}{c}{ female participants } \\
\hline male & 3.56 & 3.30 & 3.78 & 3.61 \\
faces & $(0.67)$ & $(0.43)$ & $(0.72)$ & $(0.83)$ \\
female & 4.13 & 4.33 & 4.23 & 4.30 \\
faces & $(0.71)$ & $(0.53)$ & $(0.60)$ & $(0.55)$ \\
\hline \multicolumn{5}{c}{ male participants } \\
\hline male & 2.99 & 2.97 & 3.59 & 3.54 \\
faces & $(0.90)$ & $(0.91)$ & $(0.87)$ & $(0.70)$ \\
female & 4.39 & 3.53 & 4.25 & 4.26 \\
faces & $(0.70)$ & $(0.71)$ & $(0.72)$ & $(0.73)$ \\
\hline
\end{tabular}

636 
638 Figure 1.

639
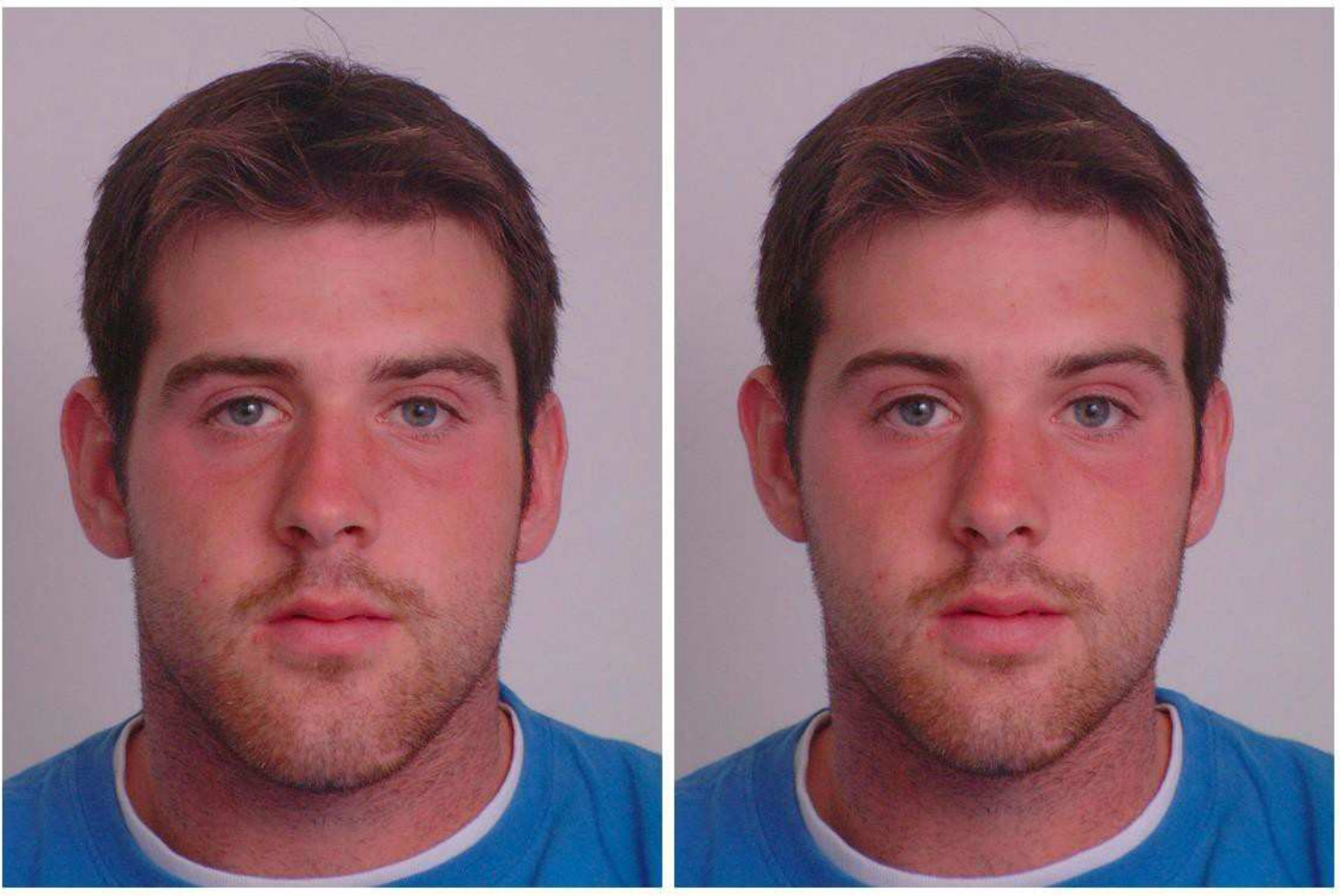

640 Figure 1. Examples of masculinized and feminized versions of face images

641 used in our experiments. 